\title{
Transitioning from a hierarchical product organization to an open platform organization: a Chinese case study
}

\author{
Jiao Luo ${ }^{1 *} \mathbb{D}$, Andrew H. Van de Ven ${ }^{1}$, Runtian Jing ${ }^{2}$ and Yuan Jiang ${ }^{2}$
}

\author{
* Correspondence: luoj@umn.edu \\ ${ }^{1}$ Carlson School of Management, \\ University of Minnesota, 321 19th \\ Avenue South, Minneapolis, MN \\ 55455, USA \\ Full list of author information is \\ available at the end of the article
}

\begin{abstract}
Organizations around the world are designing new forms of organizing in order to deal with the challenges of advances in information technology and digitization that promote increases in customization and innovation in the face of global competition. This paper presents a case study examining the challenges experienced by a large multinational firm as it transforms from a hierarchical product organization to an open platform network organization. We show that (a) role confusion, (b) control imbalance, and (c) staffing mismatches are key challenges associated with organizational redesign. The main lessons drawn from this case are discussed.
\end{abstract}

Keywords: Organization design, Corporate venture, Strategy and structure, Microenterprise, China

\section{Background}

With advances in Internet communications, robotic manufacturing technologies, and global competition, organizations are experimenting with a variety of innovative designs for organizing their businesses (Davis, 2016). Internet technologies are decreasing the costs of coordination, which enables organizations to decentralize and transform their hierarchical departments into small self-managing groups connected in open platform organizational arrangements (Altman \& Tripsas, 2014). As we examine in this paper, some of these small groups operate like self-managed and governed micro-enterprises that compete with each other and other market competitors. Organizing around micro-enterprises promotes the benefits of cohesiveness, motivation, commitment, productivity, and "a wider interaction between the organization and its environment" (Leavitt, 1975:17; Meyer, 2017). It also encourages employees to become entrepreneurs. Digital technologies permit these small groups to minimize distance from their customers, co-innovate by involving them in new product $R \& D$, and improve customer experience with mass customized products and services (Lee, Olson \& Trimi, 2012; Marquis \& Raynard, 2015).

These small groups, of course, do not achieve this alone. They are often linked as nodes into open network platforms connecting all kinds of resources within and outside of the organization (Altman \& Tripsas, 2014). Platform organizations often play "back office roles" for micro-enterprises of providing financing, accounting, HR, legal,

(c) The Author(s). 2018 Open Access This article is distributed under the terms of the Creative Commons Attribution 4.0 International License (http://creativecommons.org/licenses/by/4.0/), which permits unrestricted use, distribution, and reproduction in any medium, provided you give appropriate credit to the original author(s) and the source, provide a link to the Creative Commons license, and indicate if changes were made. 
procurement, distribution, and other capital-intensive services, which in turn permit micro-enterprises to focus on their competitive strengths (Sorensen \& Fassoiotto, 2011). While platform structures are highly flexible in recombining resources and capabilities in response to changing needs and short product life cycles, they provide a meta-organization structure (Ciborra, 1996) for gaining the economies of scale and scope that are necessary for competitive survival in a flexible manner (Zhou, 2011).

This paper examines some of the challenges and learning experiences of a large multinational company that is transitioning from a traditional hierarchical manufacturing organization to an open platform organization. It is based on a recent case study of trying to implement an alternative business model at a Chinese company, anonymously called the "Firm." Although the organizational transformation is still underway, we report preliminary findings on major challenges encountered and lessons learned to date. These challenges concern (a) role confusion, (b) control imbalance, and (c) staffing mismatches as the organizational transformation process unfolds. We think these challenges are commonly experienced and merit careful attention in managing many organizational transformation efforts.

\section{Case presentation}

Built in the 1980s, the Firm is one of the leading manufacturers of white home appliances and electronics headquartered in East China. Its main business involves researching, developing, producing, and selling various home appliances including refrigerators, washing machines, and air conditioners. In addition, the company also manages a comprehensive business system that combines $R \& D$, manufacturing, logistics, and after-sale services.

In 2015, the Firm achieved remarkable performance, with a 5-year compound profit growth rate of $35 \%$. With over 60,000 employees, the company's net profit was over 600 million USD on total revenues of over 13 billion USD. In addition to manufacturing facilities, the Firm has $R \& D$ centers in different regions in the world.

Anticipating dramatic changes on the bases of market competition and the growth of the Internet economy, the Chair and CEO was not willing to continue with the company's business model, which was obviously successful in the past. In 2014, he announced a new strategy for the Firm to transform all employees to become entrepreneurs, all departments to become micro-enterprises, and the operating company to become an entrepreneurial platform. The CEO stated,

"In the internet age we need zero distance from our customer. This is very challenging, often painful, yet very empowering transition of facing the market directly, creating value for the customer, and being rewarded by the customer (Interview with Firm CEO, May 27, 2014)."

The Firm is now in the midst of a reinvention-it is turning itself into an Internet-based "platform company" that is made up of micro-enterprises which are run by entrepreneurs. The idea is to create an organization that is extremely responsive to customer needs, and cultivates new ideas and innovates quickly with customer involvement and Internet-based smart factories producing mass-customized products.

In contrast to a closed hierarchical structure, the Firm adopts the metaphor of an "upside-down triangle," which is an inverted organization that puts front-line employees in 
micro-enterprises at the top of the structure because of their direct interactions with customers. In the middle of the triangle is the platform unit that provides resources and support, with the strategic unit supporting the platforms. Such a decentralized structure intends to highlight customer service as top priority of the whole organization, as well as to facilitate more effective information sharing and processing.

At the core of the company's change efforts is the transformation of traditional business functions and units into micro-enterprises (MEs), with each ME in charge of its own decision making in such areas as products, personnel, and finance. MEs also take control of their daily operations and human resource management. In the company, there are three types of MEs: customer-focused MEs, production-based MEs, and functional MEs. Customer-focused MEs are business groups organized around specific customers, and their primary tasks are product/service design and customer interaction. Production-based MEs are transformed from traditional operation functions (excluding sales and marketing) on the business lines, i.e., R\&D, production, and logistics. Functional MEs are developed from supporting functions such as finance and human resources. In each of these types of MEs, the process starts with a customer focus to discover customer needs; with approved business proposals, production MEs get involved in developing products that meet those needs. The whole process encourages customers' participation and input that call attention to product improvement and innovation. By the end of 2015, the Firm has 364 customer-focused MEs, 740 production-based MEs, and 21 functional MEs, totally including 60,279 employees.

As a self-sustaining market entity, an ME's sustainability is contingent upon the value it creates for its customers. Its performance management metric consists of two dimensions: market competitiveness (e.g., revenue and profit margin) and strategic alignment (i.e., the extent to which the ME's goals align with the organizational goals). Such an evaluation system directs employees to become entrepreneurs and business partners within the firm, transforming it from a business organization into a platform for venture capital investment and incubation.

Figure 1 shows the revenues and net profits of the Firm between 2011 and 2015 . The revenues and net profits remain relatively stable before the transformation. In 2015, the revenue of the Firm is 30.44 billion dollars, with $6.8 \%$ decrease comparing to 32.67 billion dollars in 2014, while its net profit is 2.90 billion dollars in 2015 , with $18.9 \%$ increase

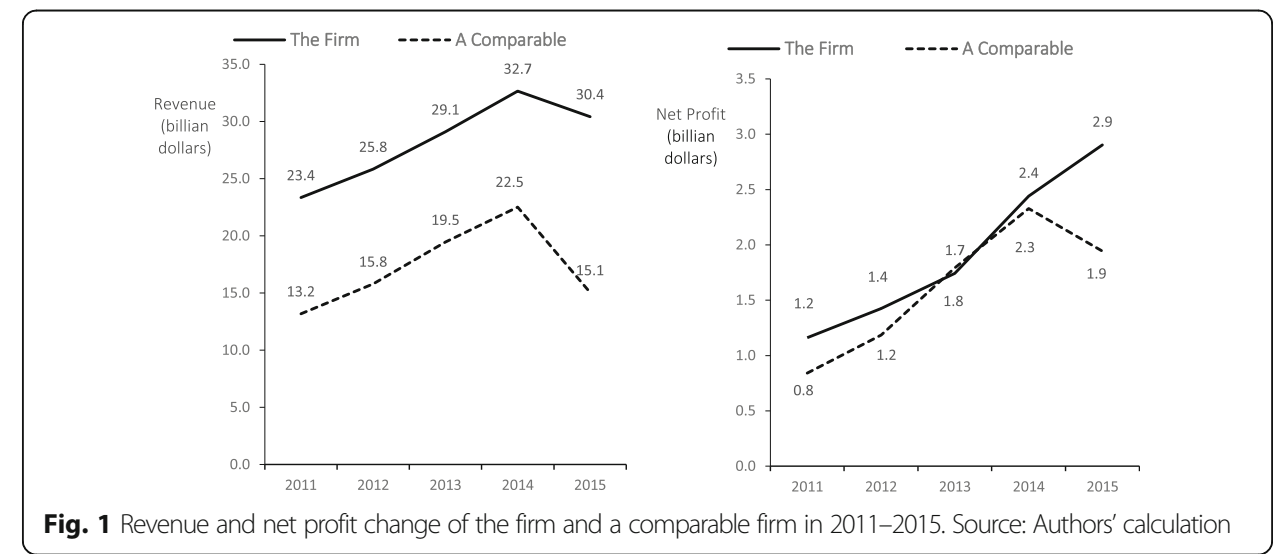

Fig. 1 Revenue and net profit change of the firm and a comparable firm in 2011-2015. Source: Authors' calculation 
comparing to 2.44 billion dollars in 2014. In contrast, its main competitor in China, labeled as "A Comparable," suffered 33.14\% loss in revenue and 16.54\% loss in net profit in 2015. The financial data show that while experiencing an economic downturn, the Firm, probably relying on its platform transformation, continues to generate net value superior to its main competitor.

\section{Research question and methodology}

Our study focused on the challenges encountered while implementing the Firm's strategy. Our interest was not in determining successes or failures of the Firm with the strategy; instead, it was to understand the process of organizational change and transformation. In particular, we designed the case study to examine the following process questions while implementing the Firm's three-prong strategy.

- At the corporate level, what challenges are encountered in transitioning the Firm's closed operating company into an open platform organization that facilitates microenterprise entrepreneurship? How are stakeholder relationships developed and maintained at different levels and units?

- At the unit/micro-enterprise level, how do transitions unfold from organizational units to micro-enterprises and how do the MEs relate to each other over time?

- At the individual level, how do transitions unfold from being employees to entrepreneurs over time?

Data on the Firm's transformation was obtained by conducting interviews, a questionnaire survey, and publicly available company reports and media. From February to March 2015, 18 1-h interviews were conducted with employees across Firm levels, including two co-CEOs, two other members of the top management team, four platform owners, seven micro-enterprise owners, and three micro-enterprise members.

Based on these interviews, we designed and administered a survey that was made available on the Firm's intranet to over 10,000 employees from September to December 2015. Only 286 survey responses were obtained from 9 platform owners, 33 microenterprise owners, and 244 micro-enterprise members. Unfortunately, survey responses were very low. Several reasons may account for the low response rate. First, while the survey was made available on the company's intranet, the company did not provide researchers' information about which employees accessed the survey on the intranet. This prevented us from conducting the standard follow-up procedures to request survey submissions and determine survey responses. This was the first company-wide survey, and the employees were inexperienced about it. About $70 \%$ of employees were manufacturing workers with high-performance pressures in factories, and they seldom accessed the company intranet for their work. In addition, data from organizational records on personnel and micro-enterprise performance were not made available. It should be remembered that the purpose of our data collection was to generate (not test) ideas and challenges in undertaking corporate transformation. As a consequence, the survey findings presented here should not be generalized beyond the 286 individuals who completed the survey. Our analysis of the survey responses provided useful insights for identifying the challenges that respondents in the organizational transitions 
were experiencing. We triangulated findings from the interviews, surveys, and public media in order to draw preliminary conclusions, as presented in the next section.

\section{Preliminary findings}

Since the organizational re-structuring process is still playing out, we can only share certain preliminary findings on the organizational design implications. The findings concern the following: (a) role confusion, (b) control imbalance, and (c) staffing mismatches as the main challenges associated with the Firm's transition process.

\section{Role confusion}

We find that while certain aspects of role assignments have been clarified and emphasized during the redesign process, other important aspects are left undefined and unattended. Specifically, the micro-enterprises do see themselves as serving customer needs, which is one of the key goals of the restructuring efforts. As evidence, Table 1 presents representative quotes from the interview transcripts that were collected by the research team between February and March 2015. Table 1 (a) suggests that the idea of being consumer oriented and deeply engaged in user interactions has become salient for many of the micro-enterprises.

Table 2 codes the interview transcripts by the units to which each interviewee belongs, as well as the functional activities performed by their units. As shown in the top left corner, all micro-enterprise leaders and members we interviewed highlighted various activities closely related to users, including product development, consumer interaction, marketing, and sales. Moreover, Fig. 2 plots the survey data on perceived organizational effectiveness (5-point scale) by user focus (6-point scale) that 33 micro-enterprise owners were asked to complete. The results suggest that the perceived effectiveness of the micro-enterprises is highly and positively correlated with user focus, further evidencing that the micro-enterprises incorporated serving customer needs as their direct roles (Table 3).

In sharp contrast to the clear role definition of the micro-enterprises and their consumer-facing activities, the platforms remain largely unclear on what roles they should and should not play. As shown in Table 2, the roles of platforms are heterogeneous and not well defined, and the platform and micro-enterprise owners have varying understanding on the question. Specifically, activities such as procurement, logistics, and HR, which are supposedly roles of platforms, are not attended to by either the platforms or the micro-enterprises. However, activities such as strategy, accounting, and stakeholder relations, which are essential roles of micro-enterprises, remained with platforms and are unattended by the micro-enterprises themselves.

Such role confusions for platforms are not unique to the Firm and reflect large challenges of fostering entrepreneurship within organizations. Sorenson and Fassoiotto (2011) listed a long list of potential roles that platforms may play, including venture capital, knowledge and skills, beliefs and values, social capital, opportunities, and common/central services, as well as technologies. What should platforms include and not include is a question that is far from being settled in the literature as well as in practice (Ciborra, 1996; Altman \& Tripsas, 2014). 
Table 1 Selected quotes from interviews

a. Role clarity

No. Quotation

1 The payment to the workers ... is decided by the consumer evaluation.

2 There was a geek user who talked his personal life with our team member [Name] for more than two hours at the midnight. If such a thing happened in the past, [Name] might hung up cause it's obviously a disruption. As to now, they appreciate each other, they are more like friends who have common interest.

3 In the past, we focus on product promotion. As for now, we gain added value from user engagement and user flows.

$4 \quad$ We started interaction with our customer at the very beginning. Some functions like aromatherapy and coupling are generated from interaction.

5 We change and focus all our energy towards the users. We very closely deal with them, from product design, development and production, all stages are closely interacted with users. All incomes for all team members are decided by the user interactions. How much you'd earn, and what's your value added...The mode of user interaction introduces a lot of new ideas. Because users are not constrained by whether the idea can be realized or not. And thus there are lots of unbounded creativity.

b. Risks and compensations

No. Quotation

6 The vital thing is the entrepreneurship, passion to realize your own dream. Meanwhile, an entrepreneur should be responsible and fearless of risks.

7 Employees become partners or stakeholders now, such as [employee A] and [employee B] of [Me A], they have shares and option. Capital can be powerful.

8 The company should be willing to take more risks on treating employees and setting strategies. For example, I think we don't dare to award a worker who originally make ten thousand yuan a year with ten million yuan, but we actually should do that. Employees must be creating ten times more economic returns when he is rewarded well. I believe this will be an improvement on our way of transforming, and it will encourage our MEs and employees to develop well.

9 We will not disband micro-enterprises if they are not profiting in a few months. The establish of these micro-enterprises are based on our main strategy, so it must succeed. What we will do is try to adjust it and try to figure out where does the problem come from, solve it, and make it profit soon. Actually the platforms should also be responsible for those who cannot profit. As a manager of the platform, we are also trying hard to help.

$$
\text { c. Independence vs. coordination }
$$

10 Many people ask us why don't we move out of the Firm's campus. I say why do we move? This is not important. Suppose I move to a place that is not far from the Firm's Road, rent an office and work from there. What it means is that the cost the setup, human resources, as well as traffic is going to be very costly. The communication cost becomes much higher that way. Because we are in the Firm's campus. If there is any dispute, we can solve quickly and early. Of course, strictly speaking, we have contractual arrangements such that all disputes can be solved in courts. But the probability of that happening is very small. We have the legal arrangement, but mostly we solve issues through communications (say, if this customer is not satisfied and what happened with after-sales service). Having such informal relationship is a huge advantage to us.

11 We have many MEs for functional areas (i.e., after-sales, quality). This is because we are taking the areas that all MEs need, and then combine them to create a new ME. This way we minimize the cost for each $M E$, and let them focus on what they need to focus on, and what they are good at doing. In the internet era, it is not about how big you are, it is about what you are good at, and whether you can maximize your strength and be differentiated. Specialized MEs can take care of things, and you just need a contractual relationship with them.

12 Our product is different from air-condition. But we share the same channel cause for now, we can't afford an independent channel. However, same channel results in resource competition. It's a very tough situation.

13 I do agree with the altruism and win-win spirit. At this Internet Age, we can't do things alone, we need allies. So, mutual help and mutual promotion are essential.

Source: Interview conducted by the research team, February-March 2015; quotes were translated into English

In summary, our findings suggest that while micro-enterprises have close relations with their customers, they are not directly engaged in devising strategy and building stakeholder relations as well as accounting and financing activities. This suggests that MEs are only half-way in becoming self-governing units (Meyer, et al., 2017). 
Table 2 Perceived responsibilities by ME, platforms, and functional units

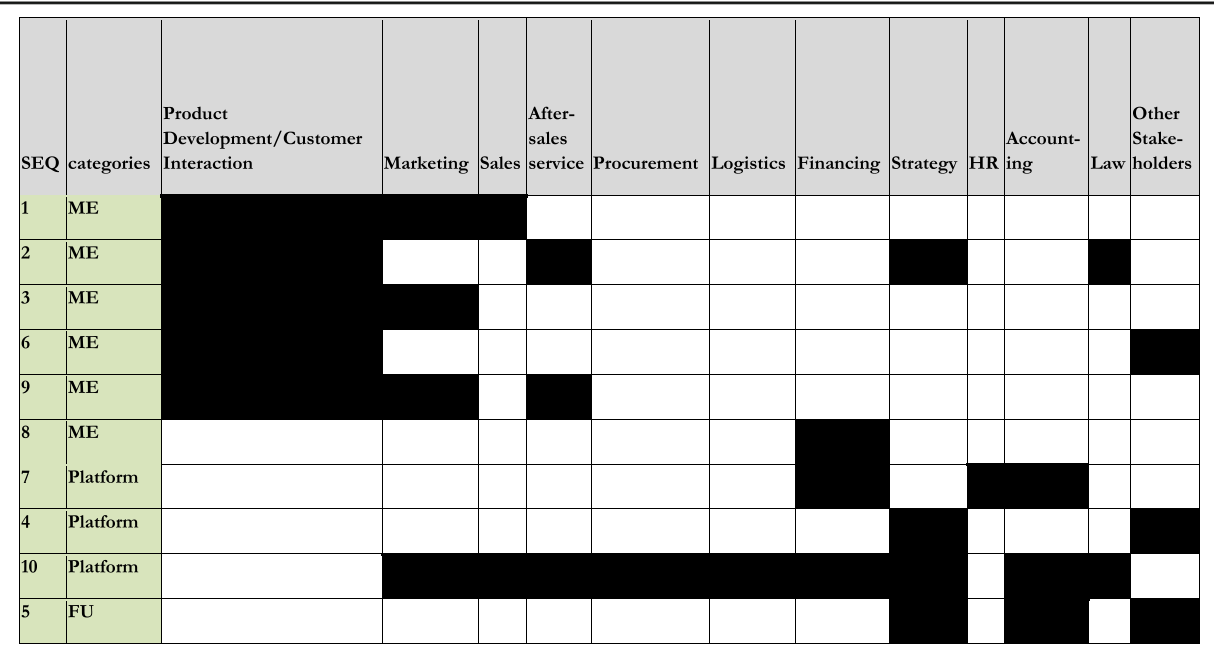

Source: Interview conducted by the research team, February-March 2015. The table summarizes the units that each interviewee belongs to, as well as the functional activities that their units are focused on that they mention during the interview

\section{Control imbalance}

A second challenge encountered during the restructuring is trading-off control and independence. On the one hand, too much control appears to exist on employees for them to become true entrepreneurs. Going back to Table 1 with representative quotes from the interview transcripts, Table 1 (b) suggests that while employees are encouraged to be entrepreneurial, they are not fully compensated for the risks they may take.

On the other hand, the micro-enterprises are still highly dependent on the Firm. Figure 3 plots the survey results where 33 micro-enterprise owners were asked which stakeholders do micro-enterprise owners interact with frequently. Owners of microenterprise frequently deal with internal constituents such as their own members, platforms, and other micro-enterprises. Similar to what we find in Fig. 2, they spend a lot less time dealing with external stakeholders, such as local government, nonprofit, media, and industry associations.

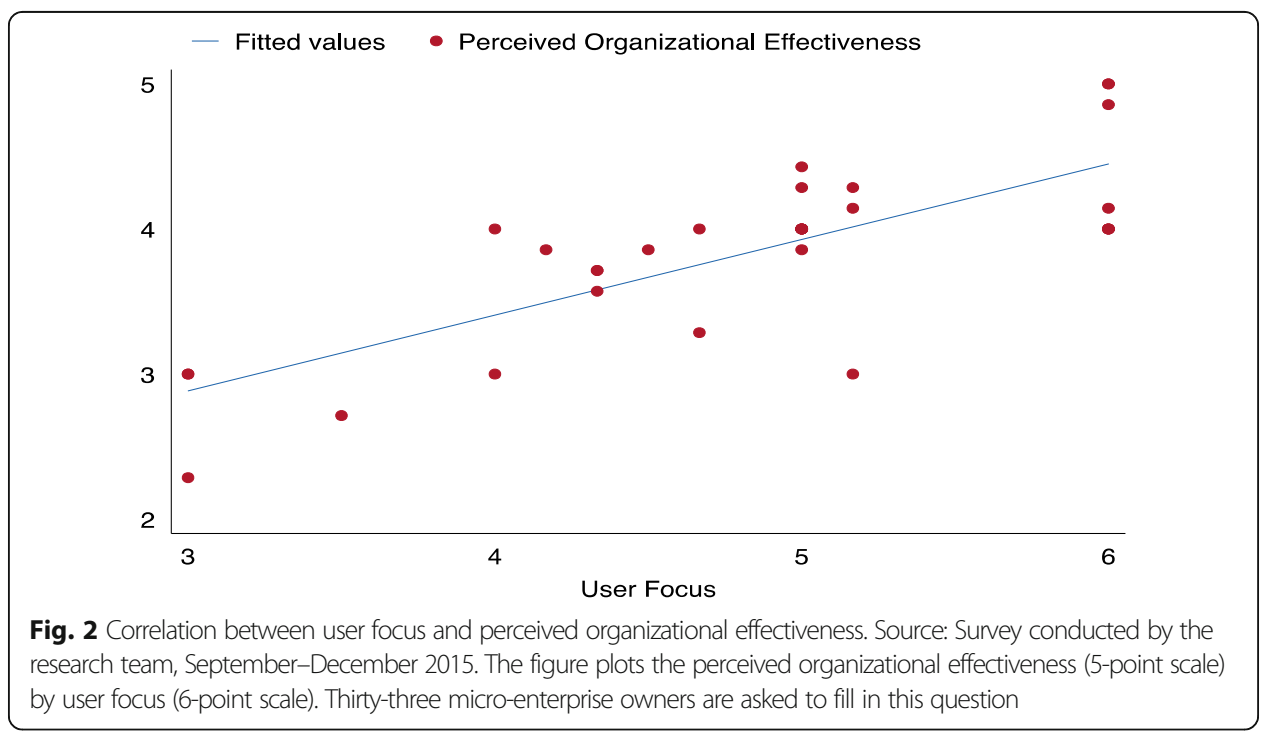


Table 3 Survey instruments

\section{User Focus:}

Adapted from Van de Ven and Chu, 1989

Num Variable Description

Var. Name

Guide

5.9 Extent your The Firm unit:

A minimizes hassles for users

B provides seamless user care

C executes smooth hand-offs

D does all it can to educate users

E anticipates user needs

F develops quality practices

\section{Perceived Organizational Effectiveness:}

From OAl by Van de Ven and Ferry, 1980

Num Variable Description

5.8 Rate your unit on:

A quality of services provided

B quantity or amount of work produced

C cost efficiency of services provided

D customer satisfaction

E financial profitability

F adaptability to change

G innovativeness of products and services Composite variable (mean of above items): OrgEffect

\section{Continuance Commitment:}

Adapted from Bergami and Bagozzi, 1996

Num Variable Description

Var. Name Guide

$3.12 \mathrm{e}$ options to leave profession (continuance: profession) (R)

$3.12 f$ option to leave The Firm (continuance: organization) (R)

Composite variable (mean of above items):

ContCommit

\section{Entrepreneurial Intentions:}

From Douglas, 2013

Num Variable Description

Var. Name Guide

5.10 To what extent agree or disagree with statements.

a Allows you to earn enough money by doing the things that you like to do best

b Capitalizes on your knowledge and enthusiasm for a particular hobby, sport, or other recreational pastime that you really enjoy doing

c Allows you to close the business and take time off, or holidays, whenever you choose

d Allows you to work at a job that is more like play than work, since you really enjoy the type of work that you would be doing

Composite variable (mean of above items): 
Table 3 Survey instruments (Continued)

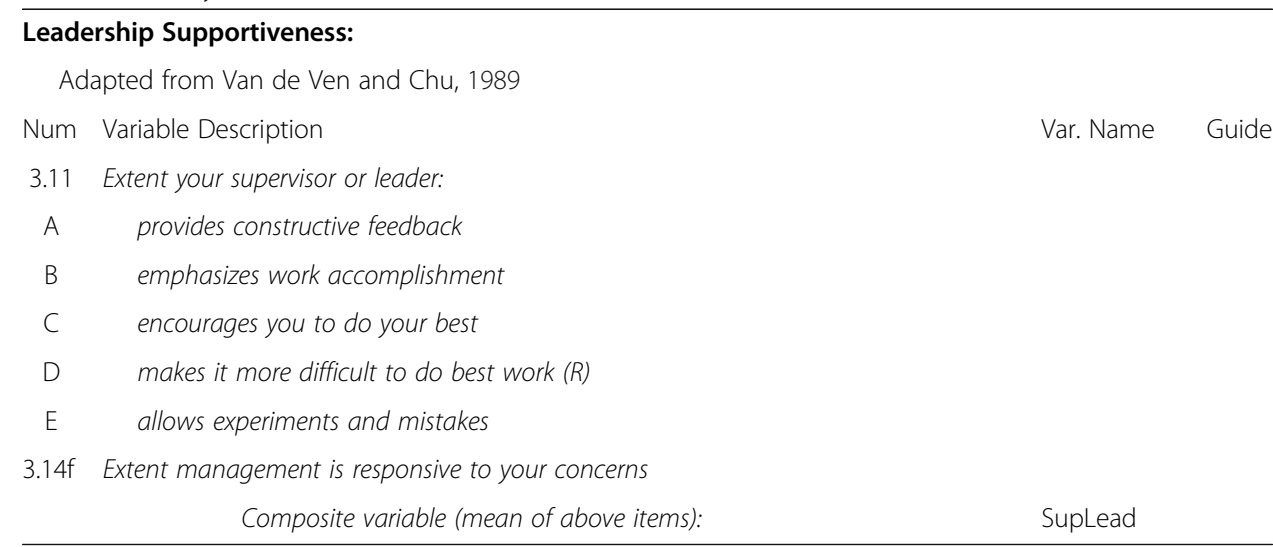

It could be the case that the Firm's relationship with stakeholders is also changing. It is interesting that $75 \%$ of the owners of micro-enterprise mention dealing with external market constituents such as external suppliers. But we lack the longitudinal data to examine if micro-enterprises focus on market stakeholders (users, platforms, other MEs, external suppliers) and nonmarket stakeholders (media, industry associations). Platforms take the lead in dealing with local government and nonprofit organizations and leave to the corporation the task of maintaining its overall cohesion and image.

Lastly, the trade-off between control and independence is reflected in the relationship across micro-enterprises. Quotes from Table 1 (c) suggest that while there are large benefits of cooperation, the process of building a cooperative system among microenterprises and platforms remains a thorny question. While innovation and customer responsiveness are the intended benefits of MEs, it may also promote excessive internal competition and undermine the cooperation needed for a large organization to perform effectively. This is especially evident in the relationships of manufacturing MEs seeking to control costs with product MEs seeking to innovate. (Meyer, et al. 2017).

\section{Staffing mismatches}

Another challenge experienced is the mismatch between the actual and ideal staffing capabilities needed to achieve expected outcomes of the restructuring. Specifically, are

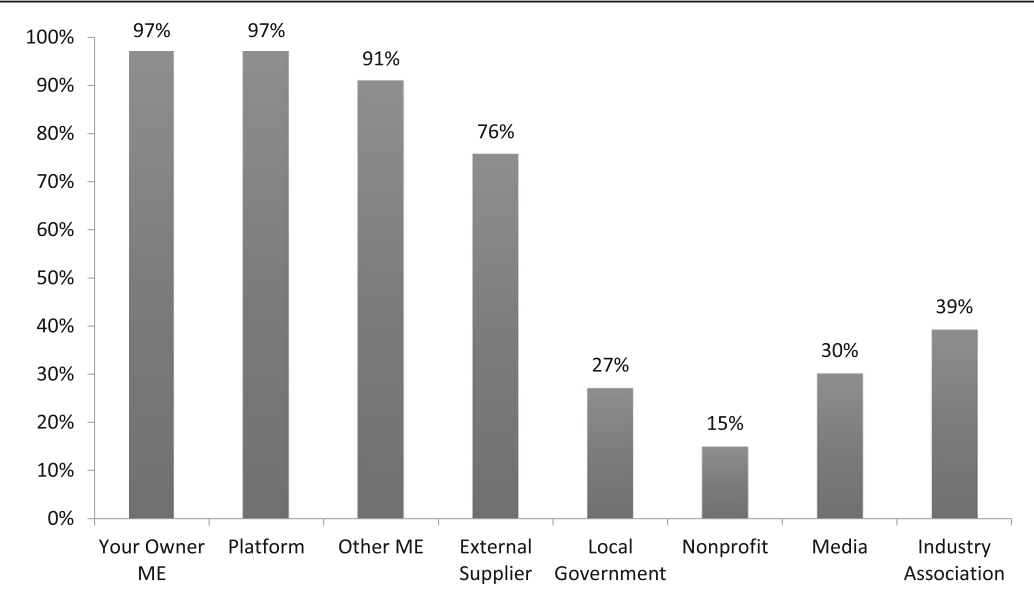

Fig. 3 Interaction intensity between ME owners and various stakeholders. Source: Survey conducted by the research team, September-December 2015. Thirty-three micro-enterprise owners are asked to fill in this question 

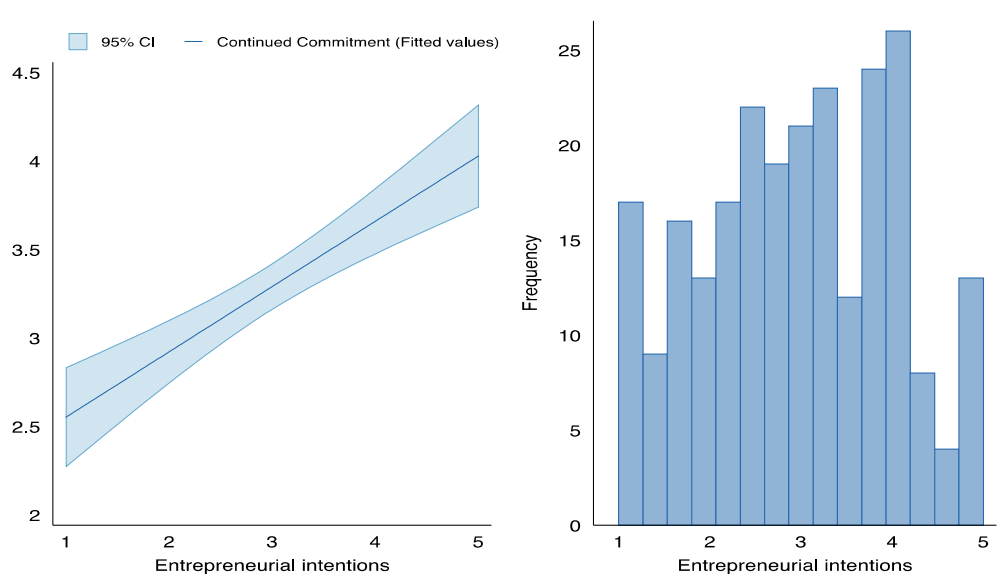

Fig. 4 Correlation between entrepreneurial intention and continued commitment. Source: Survey conducted by the research team, September-December 2015. The left figure plots the perceived continued commitment (5-point scale) by entrepreneurial intention (5-point scale). The right figure plots the distribution of entrepreneurial intention (5-point scale). All respondents are asked to fill in this question

the employees truly entrepreneurs, and in what sense? Are managers able to manage entrepreneurial ventures? We compile results from the survey from September to December 2015 with suggestive evidences to these questions.

Figure 4 (left) plots the perceived continued commitment (5-point scale) by entrepreneurial intention (5-point scale). Figure 4 (right) plots the distribution by entrepreneurial intention (5-point scale). All respondents are asked to fill these questions. The result suggests that entrepreneurial intention is a significant factor that fosters individuals' continued commitment towards the Firm. The employees that are to the left of the scale on the entrepreneurial intention are not likely to be as committed to the organization post the reorganization.

Similarly, Fig. 5 (left) plots the perceived continued commitment (5-point scale) by leadership supportiveness (5-point scale). Figure 5 (right) plots the distribution by
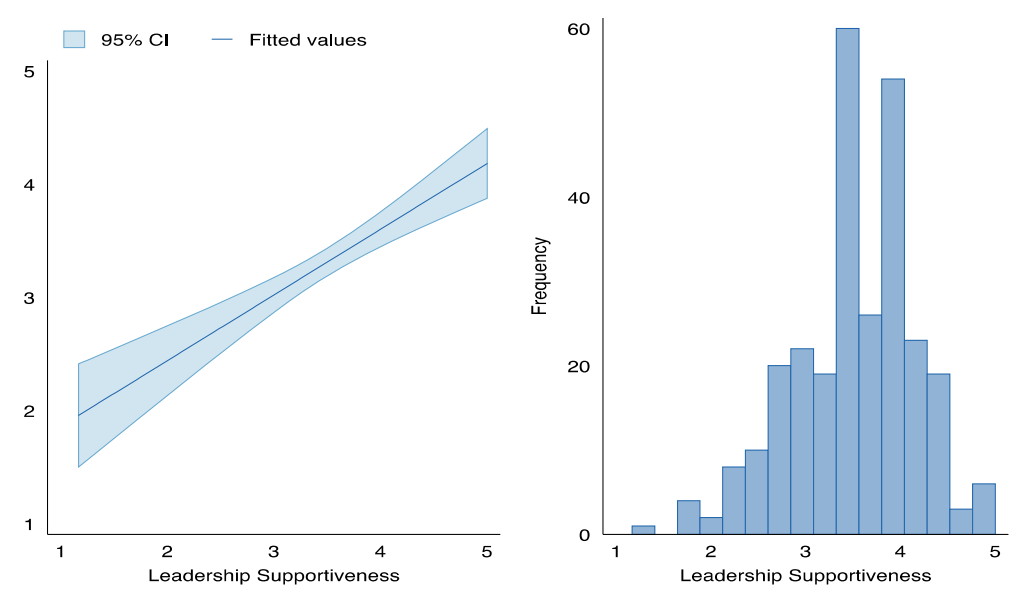

Fig. 5 Correlation between leader supportiveness and continued commitment. Source: Survey conducted by the research team, September-December 2015. The left figure plots the perceived continued commitment (5-point scale) by entrepreneurial intention (5-point scale). The right figure plots the distribution of entrepreneurial intention (5-point scale). All respondents are asked to fill in this question 
leadership supportiveness (5-point scale). All respondents are asked to fill these questions. The result suggests that supportive leadership is another significant factor that fosters individual's continued commitment towards the Firm. The supervisor personifies the organization to the employee, and a supportive leader means a great deal to the employee (Jones \& Van de Ven, 2017). The managers who are low on the scale of supportive leadership are less likely to be successful in managing employee transitions into micro-enterprise teams post the reorganization.

Taken together, changing from a hierarchical to a platform approach to organizing necessitates a transformation of both employees and managers, calling for training and development of skills and behaviors oriented towards new tasks and expectations. Our findings show that employees and managers in the Firm have yet to be equipped with needed entrepreneurship and leadership style. Besides hiring new people matching the platform organization, the organization should facilitate learning via various training programs and knowledge sharing among individuals and units (Noe, Clarke \& Klein, 2014).

\section{Discussion}

Whether market or hierarchy is more effective in organizing assets and activities to create value is an enduring question (Zenger, Felin \& Bilelow, 2011). With the introduction of Internet come opportunities for organizations to lower coordination costs and encourage more entrepreneurial, decentralized activities. This case study explores issues and challenges facing a large manufacturing firm that is transforming from a traditional hierarchical organization to an open, market-like platform that supports self-managing micro-enterprises. In particular, we found that the Firm's transition from a hierarchy to an Internet market-based platform is experiencing three key challenges, namely, role confusion, control imbalance, and staffing mismatches. No doubt, many other challenges are experienced when organizations undertake such radical transformations as the Firm does. These three challenges are important, however, because they call into question the limits of market and hierarchy organizational designs.

As market and hierarchy call for distinct roles played by actors, it is unsurprising to find employees confused about their roles in the transformation into market-hierarchy hybrids (Williamson, 1985). Our case study reveals that it is those who work on the platforms that are mostly unclear about roles and responsibilities assumed to them. Moreover, there lacks a clear understanding of responsibilities undertaken by microenterprises and by platforms. Further theoretical and empirical work are needed to identify roles and responsibilities of differing actors in open platform organizations.

The goal of infusing market elements into a hierarchical organization is to provide high-powered incentives and counterbalance costly centralized decision making. However, as reported earlier, the micro-enterprises that were surveyed lack a sense of independence and initiatives in dealing with external stakeholders. Likewise, employees have difficulties in transitioning to real entrepreneurs. This is also related to role confusions experienced by platform employees, as there is an inherent contradiction between authority-based hierarchy and decentralized, market-like entrepreneurship. Another related issue is around pricing in such internal markets. Although the Firm intends to run a market-like incentive system for micro-enterprises, the allocation of bonus and 
earnings to individual employees relies on performance appraisal by their team members (Meyer et al., 2017).

The finding of mismatched staffing reflects a reality that companies are facing when transitioning from a traditional hierarchy to an open platform organization. One way to fill the skill shortages is to hire desired entrepreneur-type job candidates from labor markets. Another way is to develop entrepreneurs in-house. Organizations are arenas for learning because they directly and indirectly shape the knowledge and skills needed for entrepreneurship (Sorensen \& Fassiotto, 2011). Thus, besides formal training programs designed for developing specific entrepreneurial capabilities, broad job design and the presence of successful entrepreneurs, for example, can both promote learning about the entrepreneurial process (Sorensen \& Fassiotto, 2011). Tushman and O'Reilly III (2002) proposed that organizational configuration needs to be transformed across four fundamental dimensions including core tasks and processes, formal organizational structure, organizational employees, and organizational culture to achieve congruence. By simultaneously balancing the fit among the four aspects and the aim of the desired change, organizations can achieve better performance than competitors. Our data show that since 2014, the Firm made tremendous changes in its core tasks, processes, and organizational structure. As a reflection, the employees exhibited strong sense of useroriented obligation, and the peripheral organizations have successfully changed from command-driven work units to proactive micro-enterprises. Of course, the other two components corresponding to the desired platform organization, i.e., employee capability and organizational culture, may be even more difficult and take longer time to realize. They raise major challenges in future organizational transformations. How to transform the previous unpretentious and disciplined employees into creative and adventurous entrepreneurs? How to change the previous execution-oriented organizational culture into innovation-oriented one?

Changes in the sharing economy plus information and technology are driving many firms to restructure. Although transitions from hierarchy to platform designs have become a commonplace for software and service-based companies, it could be questioned if this business model is appropriate for capital-intensive manufacturing companies. Along this line, the Firm's CEO admits that his strategy is different from traditional theories.

"Ronald Coase [and Oliver Williamson] had a theory about the boundaries of companies: if you have a competitive product, expand production; otherwise, shrink your boundaries. Coase's theory was correct for his world. But that world had no internet. In a hierarchy, whoever has more resources has broader boundaries. However, as today's companies are integrated with the network, to some extent, resources are infinite. In this sense, we are building a borderless ecosystem to co-create and win together (CEO presentation, September 19, 2015)."

As this quote suggests, which activities are handled by the market and which within the hierarchy determines the boundary of a firm. Based on theories of firm-market boundary, Zenger et al. (2011) discuss the virtues and failures of markets and hierarchies. They argue that markets provide high-powered incentives through competition, efficient information aggregation through prices, and crowd-sourcing problem-solving, but markets fail to support specialized investments, complex coordination, and when institutions are weak. Hierarchical transactions, on the other hand, provide access to control and authority and to shape complex coordination and motivation in being a 
part of a collective mission, but organizations fail due to diminishing returns to scale, political behavior, social commitments, fairness comparisons, and when employees respond to hierarchy and not users in the market. The CEO's strategy provides a hybrid market-hierarchical design that infuses market into the organization with decentralization and disaggregation of business operations and pushes organizational units and employees into the market as micro-enterprises and entrepreneurs. Zenger et al. point out that this form of hybrid organization is no panacea and can result in highly unstable solutions with their own unique costs and management challenges. Further study of this and other organizational transformations are needed to gain an empirical understanding of the novel experiments organizations are exploring in designing their organizations in this Internet era.

Last, it is worth pointing to the specific context in which the Firm initiated its transformation. As China has experienced dramatic changes since its reform and opening from the end of the 1970s, change becomes a normal state for the country. This is also consistent with ancient Chinese philosophy of yin-yang, which emphasizes constant and cyclical change and mutual transformation between contradictory forces (Jing \& Van de Ven, 2014). Hence, the presence of the main challenges discovered in this case study, which embody the inherent conflicting demands between market and hierarchy, may be relatively conservative comparing to those during similar organizational transformations in other cultural contexts.

\section{Conclusions}

As Internet technologies lower the costs of coordination, more and more hierarchical organizations start to transform into small self-managing and governing groups, infusing market-like elements to create high-powered incentives. This case study examines such a transformation in a large manufacturing firm and identifies three key challenges. The analysis of these challenges reveals inherent, enduring tensions and contradictions facing market-hierarchy hybrid organizations, which call for further theoretical and empirical investigations of traditional organizations transforming in the open, Internet era.

\section{Acknowledgements}

We are grateful to editor Charles C. Snow and two anonymous reviewers for the suggestions and guidance. We also acknowledge the comments and feedback from the participants in the Organizational Design Community 2016 Annual Conference and the University of Minnesota Carlson SME Seminar Series.

Runtian Jing thanks the Key Research Project of the National Natural Science Foundation of China (NSFC) (grant number 71432005) for the financial support on this research. Yuan Jiang thanks the National Natural Science

Foundation of China (grant number 71672111) for the financial support on this research.

\section{Funding}

This paper benefited from the Key Research Project of the National Natural Science Foundation of China (NSFC) to the third author (grant number 71432005), as well as the National Natural Science Foundation of China (grant number 71672111) to the fourth author.

Availability of data and materials

The dataset(s) supporting the conclusions of this article will not be shared.

Authors' contributions

The paper was developed and written collaboratively by all four authors. All four authors read and approved the final manuscript. 


\section{Publisher's Note}

Springer Nature remains neutral with regard to jurisdictional claims in published maps and institutional affiliations.

\section{Author details}

${ }^{1}$ Carlson School of Management, University of Minnesota, 321 19th Avenue South, Minneapolis, MN 55455, USA. ${ }^{2}$ Antai College of Economics and Management, Shanghai Jiao Tong University, Huashang Road 1954, Shanghai 200052, China.

Received: 17 October 2017 Accepted: 6 December 2017

Published online: 05 January 2018

\section{References}

Altman, E.J. Tripsas, M. 2014. Product to platform transitions: organizational identity implications, Harvard Business School, working paper 14-045

Bergami M, and RP Bagozzi. 1996. Organizational identification: conceptualization, measurement, and nomological validity. Working paper, University of Bologna/University of Michigan

Ciborra CU (1996) The platform organization: recombining strategies, structures, and surprises. Organ Sci 7(2):103-118

Davis GF (2016) The vanishing American corporation: Navigating the hazards of a new economy. Berrett- Koehler Publishers. Oakland, CA.

Douglas EJ (2013) Reconstructing entrepreneurial intentions to identify predisposition for growth. J Bus Ventur 28(5):633-651

Jing R, Van de Ven AH (2014) A yin-yang model of organizational change: the case of Chengdu bus group. Manag Organ Rev 10:29-54

Jones SL, Van de Ven AH (2016) Changing nature of change resistance: An examination of the moderating impact of time. Journal of Applied Behavioral Science 52(4): 482-506.

Leavitt HJ (1975) Suppose we took groups seriously. In Cass EL, Zimmer FG (eds) Man and work in society. Van Nostrand Reinhold, New York, pp 67-77.

Lee SM, Olson DL, Trimi S (2012) Co-innovation: convergenomics, collaboration, and co-creation for organizational values. Manag Decis 50(5):817-831

Marquis C, Raynard M (2015) Institutional strategies in emerging markets. Acad Manag Ann 9(1):291-335

Meyer M, Lu L, Peng J, Tsui A (2017) Micro-divisionalization: using teams for competitive advantage. Academy of Management Discoveries 3(1):3-20

Noe RA, Clarke ADM, Klein HJ (2014) Learning in the twenty-first-century workplace. Annu Rev Organ Psych Organ Behav 1:245-275

Sorensen JB, Fassiotto MA (2011) Organizations as fonts of entrepreneurship. Organ Sci 22(5):1322-1331

Tushman ML, O'Reilly CA III (2002) Winning through innovation: a practical guide to leading organizational change and renewal. Harvard Business Review Press

Van de Ven AH, Chu Y (1989) A psychometric assessment of the Minnesota innovation survey, chapter 3. In: Van de Ven $\mathrm{AH}$, Angle HL, Poole MS (eds) Research on the management of innovation: the Minnesota studies. Ballinger/ Harper \& Row, New York, pp 55-104

Van de Ven AH, Ferry DL (1980) Measuring and assessing organizations. John Wiley \& Sons, New York Williamson OE (1985) The economic institutions of capitalism. Free Press, New York

Zenger T, Felin T, Bigelow L (2011) Theories of the firm-market boundary. Acad Manag Ann 5(1):89-133

Zhou YM (2011) Synergy, coordination costs, and diversification choices. Strateg Manag J 32(6):624-639

\section{Submit your manuscript to a SpringerOpen ${ }^{\circ}$ journal and benefit from:}

- Convenient online submission

- Rigorous peer review

Open access: articles freely available online

High visibility within the field

- Retaining the copyright to your article 